\title{
Detection and Classification of Power Quality Disturbances in the Supply to Induction Motor Using Wavelet Transform and Neural Networks
}

\author{
Sridhar. S, K. Uma Rao and Sukrutha Jade
}

\begin{abstract}
This paper aims to represent a proposition of an innovative and novel methodology applicable in detecting and classifying the power quality disturbances present in the supply to the induction motor. In all practicality, considering circumstantial real world applications, induction motors are usually operated on load. If the supply voltage is varied in any way, it would adversely affect the normal operation of the motor. In the present work, a healthy induction motor is subjected to power quality disturbances like balanced voltage sag, balanced voltage swell, unbalanced voltage sag and unbalanced voltage swell. For the purpose of detecting these power quality disturbances, discrete wavelet transform is applied to the stator current of the induction motor. The stator current wavelet coefficients are fed as input to the neural network for the classification purpose. Radial basis neural network and feed forward neural network have been independently trained and tested. The observation about the feedforward network having higher performance efficiency as compared to the radial basis network, has been seen.
\end{abstract}

Index Terms - Induction motor, power quality disturbances, discrete wavelet transforms, feedforward neural network, radial basis neural network.

\section{INTRODUCTION}

$\mathrm{D}$ ESPITE espite several precautions taken, supply in the grid is never perfectly balanced. Due to this imbalance in the supply, a lot of harmonics are generated which will lead to increase in losses and decrease in efficiency of the machine which is directly connected to them. If an induction motor is subjected to power quality (PQ) disturbance repeatedly, when operating on critical loads, it leads to its malfunctioning and would also lead to internal failures in the machine. Along with unbalanced voltage, the other power quality (PQ) disturbances whose effect is detrimental to the operation of a healthy induction motor are voltage sag, swell, harmonics, short interruptions, impulse surges, overvoltage and under voltage [1-2].

Sridhar. S, is with Department of Electrical and Electronics Engineering, RNS Institute of Technology, VTU, Bangalore, India, (e-mail: prof_sridhar6@rediffmail.com).

K.Uma Rao, is with Department of Electrical and Electronics Engineering, R.V College of Engineering, VTU, Bangalore, India, (e-mail: umaraok@rvce.edu.in).

Sukrutha Jade, is with Robert Bosch Engineering and Business Solutions Bangalore, INDIA (e-mail: sukrutha.jade@gmail.com).
Identification and mitigation of $\mathrm{PQ}$ disturbances are of primary concern for power quality engineers. Since power quality disturbances are non-stationary in nature, it calls for advanced tools and techniques for its analysis. Though Fast Fourier Transforms (FFT), Short Time Fourier Transforms (STFT) are good signal processing techniques, they suffer from the fact that FFT provides only spectral information of the signal without time localization, and STFT provides fixed window width, which is more suitable for stationary signals. Wavelet transform is an excellent tool for the analysis of notstationary signal as it employs a flexible window to obtain both time and spectral information of the signal. These signal processing techniques in conjunction with certain classification techniques like a neural network, fuzzy logic, neuro- fuzzy, support vector machine and expert systems have been used in the past for the classification of the power quality disturbances [3-14]. Chuah Heng Keow et al [15] has proposed a scheme for enhancing power quality problem classification based on wavelet transform and a rule-based method.

Primarily, this paper aims to categorize the balanced supply to the induction motor from balanced voltage sag, balanced voltage swell, unbalanced voltage sag and unbalanced voltage swell in the magnitude of the supply. A 3 phase, $3.2 \mathrm{KW}$, $400 \mathrm{~V}, 50 \mathrm{~Hz}, 4$ pole induction motor is selected to perform the simulation. The MATLAB SIMULINK software has been employed to carry out the entire simulation. Samples of the stator current of the induction motor are taken with a sampling frequency of $100 \mathrm{KHz}$ and is processed by an $11^{\text {th }}$ level Daubechies-9 (DB9) wavelet for the efficient extraction of the signatories of the disturbances. Multilayer feedforward neural network (FFNN) and radial basis neural network (RBNN) are independently trained and tested for the identification of an optimal network for the classification of the disturbance. The classification accuracy of all the networks are compared and presented.

\section{FEATURE EXTRACTION USING WAVELET TRANSFORM}

The detection of PQ disturbance involves feature extraction, followed by classification. The discrete wavelet transform is applied to the stator current for extracting the signature of the fault. In each step, the wavelet transform applies the scaling function and wavelet function to the input data. Wavelet 
decomposition is achieved by passing the input sampled signal through a high-pass filter $\mathrm{g}(\mathrm{n})$ and a low pass filter $\mathrm{h}(\mathrm{n})$ as seen in Fig 1. At each level, half of the signal samples are eliminated. At the end of first level of decomposition, the resultant approximate $\left(\mathrm{cA}_{1}(\mathrm{n})\right)$ and detail coefficients $\left(\mathrm{cD}_{1}(\mathrm{n})\right)$ are obtained, which are given by

$$
\begin{aligned}
& \mathrm{cA}_{\mathrm{i}}(\mathrm{n})=\sum k f(n) * h_{d}(-k+2 n) \\
& \mathrm{cD}_{\mathrm{i}}(\mathrm{n})=\sum k f(n) * g_{d}(-k+2 n)
\end{aligned}
$$

The second level approximate $\left(\mathrm{cA}_{2}(\mathrm{n})\right)$ and detail coefficients $\left(\mathrm{cD}_{2}(\mathrm{n})\right)$ are based on level 1 approximate coefficients $\left(\mathrm{cA}_{1}(\mathrm{n})\right)$. The iteration of this process continues till ' $n$ ' levels and ends when all the wavelet coefficients are known. Fig 2 gives a three level wavelet decomposition tree. The wavelet coefficients determine whether there is a discontinuity in the function or not. These coefficients are fed as input to neural networks for training.

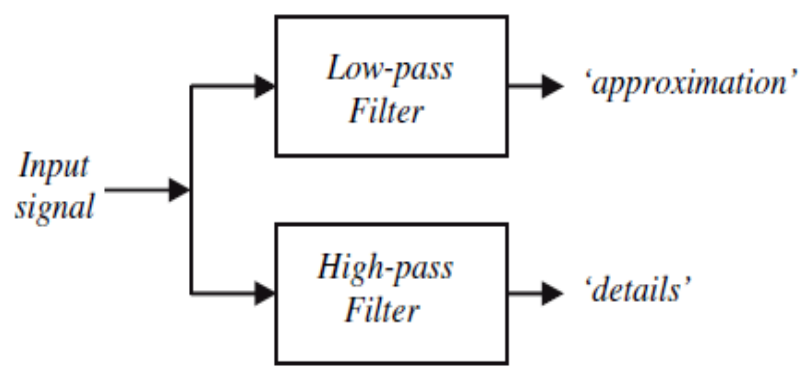

Fig. 1. one level decomposition

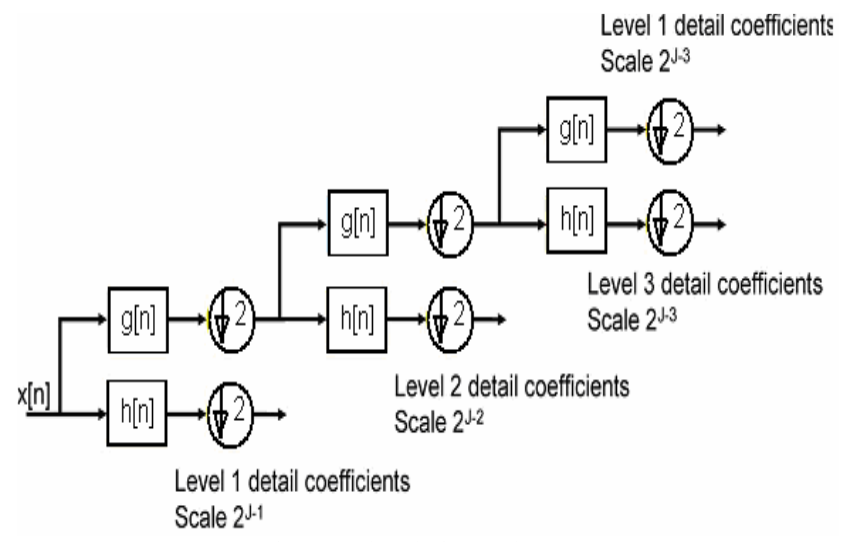

Fig. 2. 3 leveled wavelet tree.

\section{CLASSIFICATION USING NEURAL NETWORK}

Neural networks have been extensively used for the classification because of their large data handling capability. They are used to recognize and classify complex fault patterns without much knowledge about the system they deal with. The neural networks are described by the transfer function of their neurons, by training algorithm and by the connecting formula. Two different neural networks are considered in this paper.

1. Feed forward neural network

2. Radial basis neural network

\section{A. Feed Forward Neural Network}

Fig. 3 shows the network architecture of the feed forward neural network whose overall input-output behavior is determined by a collection of changeable parameters. Given the inputs $x=\left[x_{1}, x_{2}, x_{3}, \ldots ., x_{n}\right]^{T}$ and weights $w$, the neural network computes the output $y=\left[y_{1}, y_{2}, y_{3}, \ldots . ., y_{n}\right]^{T}$. The network contains a set of source nodes that comprise of the input layer, 1 or more hidden layers, and an output layer. The propagation of the flow of the input signal through the network occurs in the forward direction on a layer-by-layer basis. There is no link between nodes in the same layer. The output of the $j$ th node $\mathrm{o}_{\mathrm{f}}$ in layer $l$, for $j=1,2, \ldots, k$ can be found from the quantity expressed as,

$$
o_{j}=f\left(\sum_{i=1}^{k} w_{j i} v_{i}+b_{j}\right)=f\left(w_{j}^{T} V+b_{j}\right)
$$

Where $b_{j}$ is the bias of the $j^{\text {th }}$ neuron, $w_{j i}$ are weighted; $v_{i}$ are inputs and $\mathrm{f}$ is the activation function. The sigmoid function is the most popular activation function because of its similarity to the behavioral property of many biological neurons. The sigmoid function can be expressed as,

$$
o_{j}=\frac{1}{1+e^{-\left(w_{j}^{T} V+b_{j}\right)}}
$$

During the feed-forward computation, the neural network weights $w$ is fixed. This network is usually preferred because of its modularity, i.e., nodes in the same layer have the same functionality about input vectors. The mapping between input and output nodes may be either a linear or highly nonlinear relationship depending upon the activation function used in the network. Back propagation algorithm is a very commonly used training algorithm for training the neural networks.

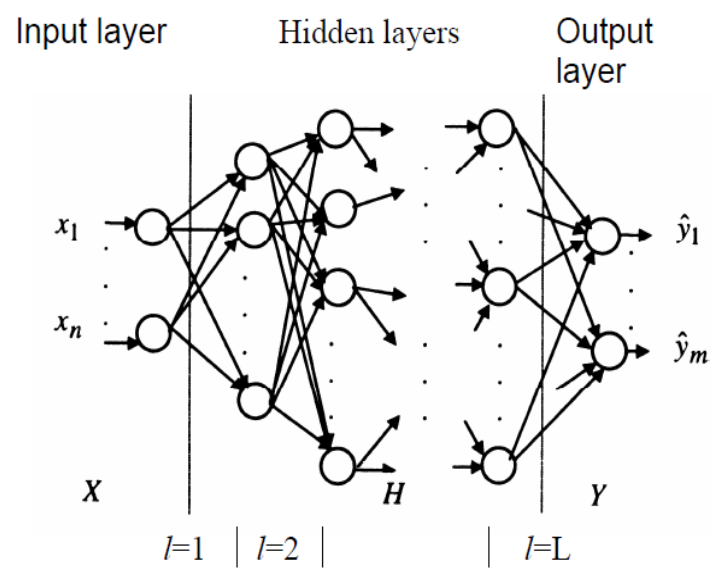

Fig. 3. Multilayer feeds forward network

\section{B. Radial basis neural network}

The block diagram of a version of an RBF classifier with one hidden layer is shown in Fig. 4. Each unit in the hidden layer of the RBF network has its centroid, and for each input 
$\mathrm{x}=\left(\mathrm{x}_{1}, \mathrm{x}_{2}, \ldots, \mathrm{x}_{\mathrm{r}}\right)$, it computes the distance between $\mathrm{x}$ and its centroid. Its output is a nonlinear function of the distance. Thus, each kernel node in the RBF network computes an output that depends on a radially symmetric function, and usually, the strongest output is obtained when the input is near the centroid of the node. For $r$ input nodes and $m$ output nodes, the overall response function without considering nonlinearity in an output node has the following form:

$$
\sum_{i=1}^{M} w_{i} \cdot K\left(\frac{x-Z_{i}}{\sigma_{i}}\right)=\sum_{i=1}^{M} w_{i} \cdot g\left(\frac{\left\|x-Z_{i}\right\|}{\sigma_{i}}\right)
$$

where $\mathrm{M} \in \mathrm{N}$ the set of natural numbers is the number of kernel nodes in the hidden layer, $\mathrm{w}_{\mathrm{i}} \in \mathrm{R}^{\mathrm{m}}$ is the vector of weights from the $\mathrm{i}^{\text {th }}$ kernel node to the output nodes, $x$ is an input vector, $\mathrm{K}$ is a radially symmetric kernel function of a unit in the hidden layer, $\mathrm{z}_{\mathrm{i}}$ and $\sigma_{\mathrm{i}}$, are the centroid and smoothing factor (or width) of the $\mathrm{i}^{\text {th }}$ kernel node, respectively, and $\mathrm{g}:[0, \infty) \rightarrow \mathrm{R}$ is a function called the activation function, which characterizes the kernel shape.

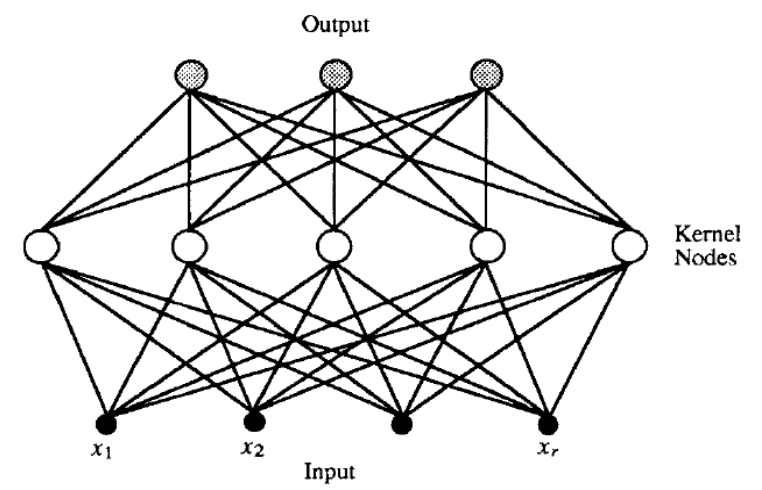

Fig. 4. A radial basis function network

The commonly used radial basis activation functions are multiquardratic and Gaussian. The multiquardratic function is given by

$$
p(\gamma)=\frac{1}{\left(c^{2}+\gamma^{2}\right)^{\alpha}}, \alpha>0
$$

and Gaussian function is given by,

$$
p(\gamma)=\exp \left(-\gamma^{2}\right)
$$

\section{PROPOSED METHODOLOGY}

In identifying the PQ disturbance, extracting features, and characteristics is the primary step. When the machine is normally running on load. The sample of stator currents are taken with a sampling frequency of $100 \mathrm{KHz}$ for the extraction of signature of the fault and is processed by Ann $11^{\text {th }}$ level DWT. The methodology proposed in this paper is designed to recognize

- Balanced sag and unbalanced sag as seen in Fig. 5

- Balanced swell and unbalanced swell as seen in Fig. 6

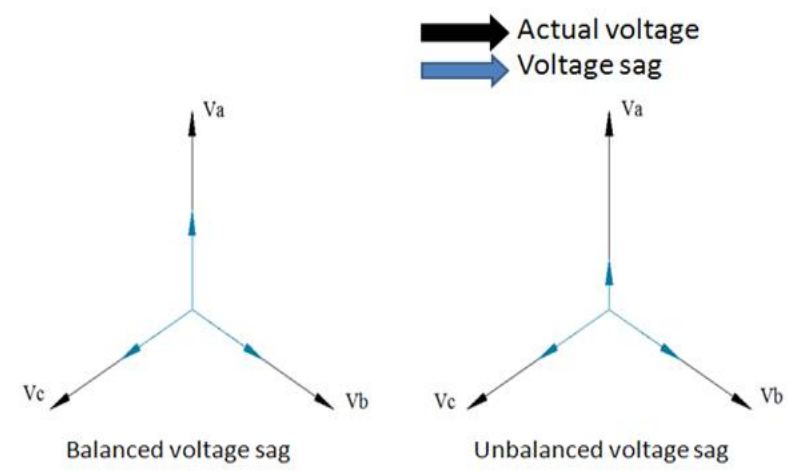

Fig. 5. Pictorial representation of balanced and unbalanced sag.

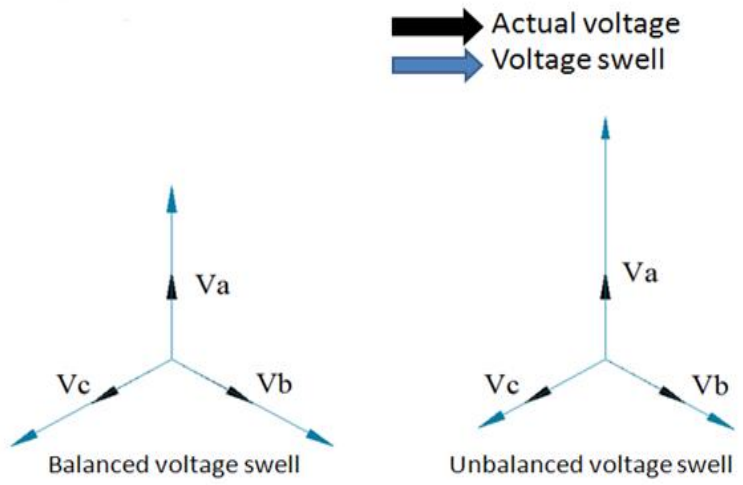

Fig. 6. Pictorial representation of balanced and unbalanced swell.

The final classification of PQ disturbances is obtained using neural networks, which takes wavelet coefficients as input. Fig. 7 shows the generalized block diagram of the neural network. The target vector consists of 3 columns.

- The first column $\left(\mathrm{y}_{1}\right)$ indicates the health of the supply (1for balance or 0 for unbalancing).

- The second column $\left(\mathrm{y}_{2}\right)$ indicates sag/ swell if any in present in the supply voltage $(-1$ indicates sag and +1 indicates swell). If the supply is balanced with no sag and swell, then this column indicates 0 .

- The third column $\left(\mathrm{y}_{3}\right)$ provides the percentage of sag or swells present if any.

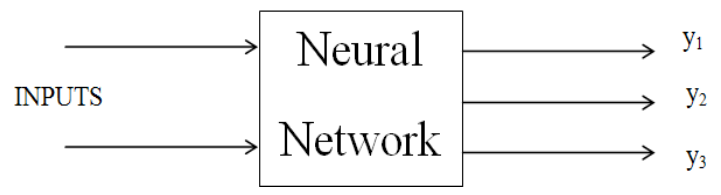

Fig. 7. Generalized block diagram of neural network

Before its utilization in the classification process, the neural network is thoroughly trained. The proposed methodology is implemented using the following steps.

Step 1. Sample the stator current of the induction motor.

Step 2. Computation of the wavelet coefficient of the stator current is done.

Step 3. The so obtained wavelet coefficients are given as input to the neural network. 
Step 4. Classification of the type of existing voltage variation is done.

Step 5. The type of voltage variation is displayed if found to exists.

Step 6. Display the percentage of voltage variation if any.

These steps are executed for both FFNN and RBNN. The neural network which gives the best classification is finally considered. The Simulink block diagram used for the creation of the PQ disturbances in the supply of the induction motor is given by Fig. 8 . The three phase programmable voltage source in varied for obtaining different types of PQ disturbances. The three phase VI measurement block is used to observe the variations in the supply voltage. A 3 phase, $3.2 \mathrm{KW}, 400 \mathrm{~V}$, $50 \mathrm{~Hz}, 4$ pole induction motor is selected to perform the simulation. The induction motor is operated at full load, with a full load torque of $30.25 \mathrm{~N}-\mathrm{m}$. The novelty of the proposed methodology is that one phase stator current (phase A) in alone used for obtaining the signature of the PQ disturbances, unlike other cases where all the 3 phase currents are used for obtaining the signature of the PQ disturbances.

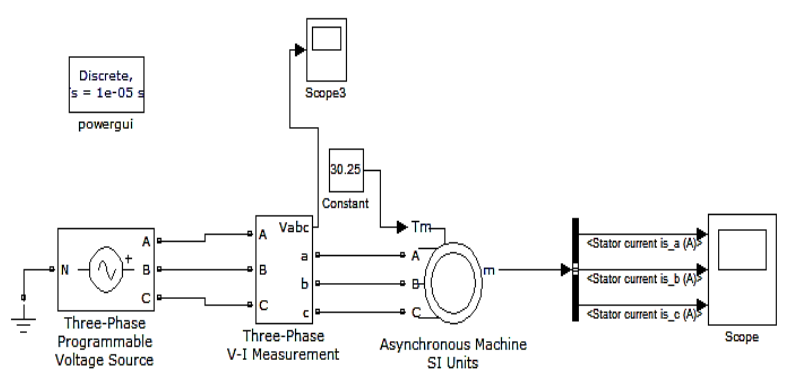

Fig. 8: Matlab/ Simulink block diagram.

\section{RESULTS AND DISCUSSION}

The stator current of phase A corresponding to balanced supply, supply with balanced sag and unbalanced sag, supply with balanced swell and unbalanced swell are as given in Fig. 9 to Fig 13.

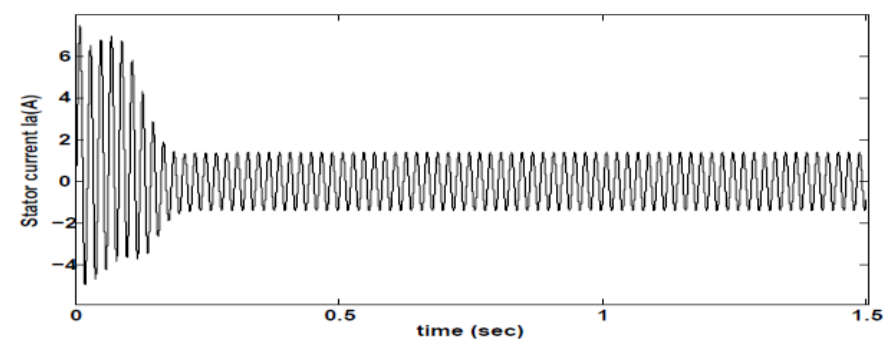

Fig.9. Stator current of healthy machine with balanced supply

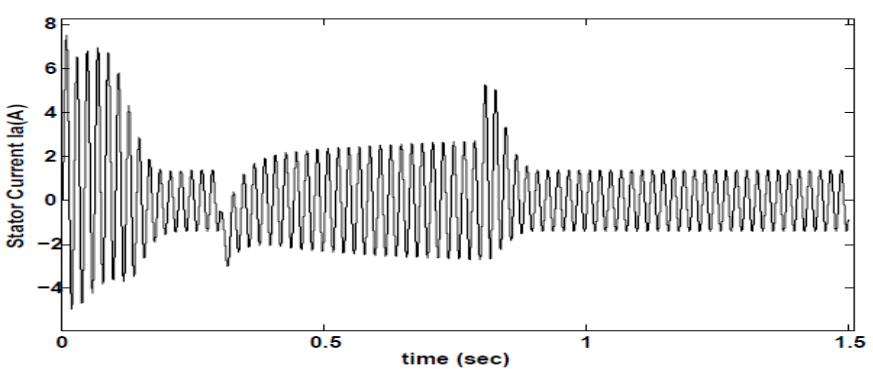

Fig.10. Stator current of healthy machine supplied with $40 \%$ sag in the supply

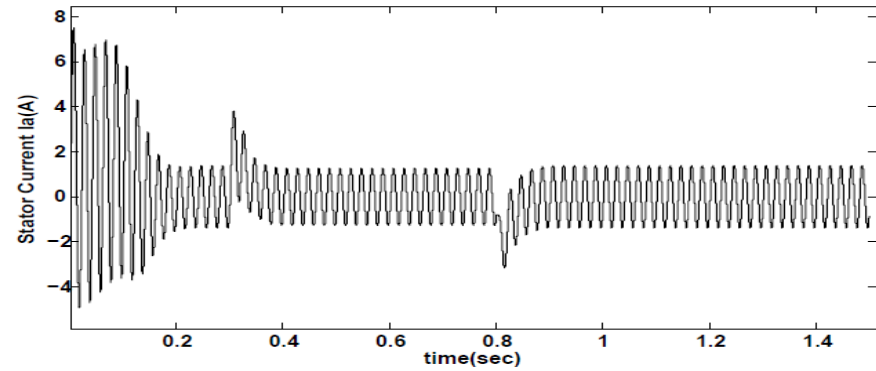

Fig.11. Stator current of healthy machine supplied with $40 \%$ swell in the supply

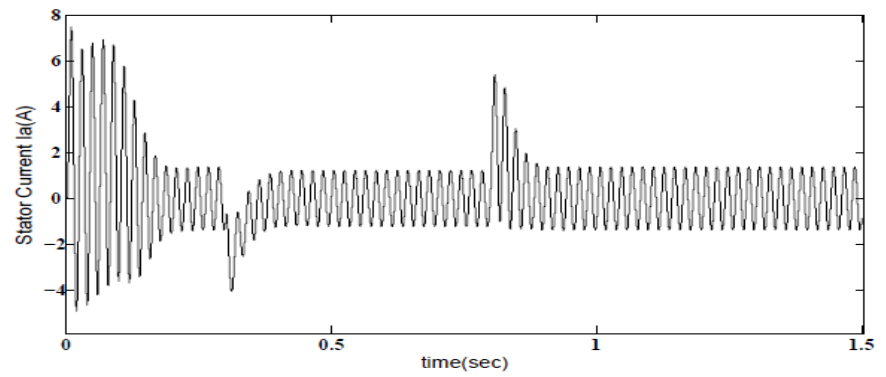

Fig.12. Stator current of healthy machine supplied with $40 \%$ unbalanced sag in the supply

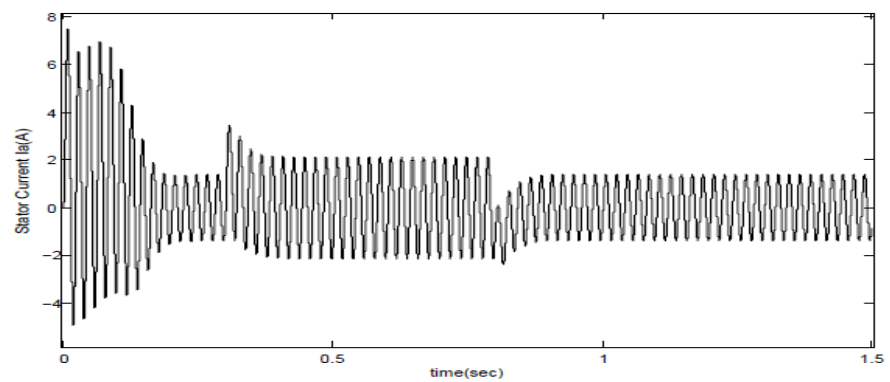

Fig.13.Stator current of healthy machine supplied with $40 \%$ unbalanced swell in the supply

The sample of the stator currents are taken with a sampling frequency of $100 \mathrm{KHz}$. The type of the mother wavelet chosen, the order of the wavelet and the number of decomposition levels are crucial for obtaining an effective output. In the present work, the suitability of the Daubechies wavelet-9 (DB9) has been ascertained, after several comparative studies between different wavelets. The number of levels of decomposition $\mathrm{L}$ is calculated according to the following formula [16]. 


$$
\mathrm{L} \geq \operatorname{int}\left[\frac{\log \left(\frac{f_{s}}{f}\right)}{\log 2}\right]
$$

Where $f_{s}$ is the sampling frequency and $f$ is the supply frequency of the stator current. For a $50 \mathrm{~Hz}$ signal with a sampling frequency of $100 \mathrm{KHz}$, the number of levels of decomposition is found to be 11 as calculated from equation (8). The $11^{\text {th }}$ level detailed coefficients are feed as inputs for further classification using neural networks. The final stage involves classification of the PQ disturbances using suitable network architecture

\section{A. Classification using feedforward neural networks}

The training of the neural network has been performed taking 37 inputs ( 1 balanced supply and 36 cases of PQ disturbance in the supply voltage), each containing 114 wavelet coefficients. During the training procedure, observation has been made regarding the fact that the selection of the neural network architecture, i.e., the number of layers, the number of neurons in each layer and the activation function play an essential role towards successful classification. Hence considering all these parameters, a feed forward neural network was created using Conjugate gradient backpropagation with Powell-Beale restarts as training function. Table 1 shows the number of hidden layers, number of neurons in the hidden layer with its transfer function, number of iterations, execution time, gradient, performance and classification accuracy of the proposed network.

Though faster performance with reduced number of the epoch, and faster convergence with accurate classification is always preferable, in practice a compromise has to be made with few of these parameters, as an ideal neural network is never realizable. The ultimate aim of the FFNN is always to obtain good classification accuracy. The corresponding parameters of the network for the highest accuracy are highlighted in Table-I. The network contains 1 input layer, 2 hidden layers with 750 neurons and 600 neurons respective layers, and 1 output layer with 3 neurons. The tan-sigmoid transfer function is used for training the hidden layers while purelin transfer function is used for training the output layer. Fig. 14 shows the performance plot of the proposed network. Linear regression between the output of the neural network and the target is performed. The regression coefficients show that the target and ANN output values match very closely as seen in Fig. 15.

TABLE I

FEEDFORWARD NEURAL NETWORK WITH CONJUGATE GRADIENT BACKPROPAGATION WITH POWELL-BEALE RESTARTS AS TRAINING FUNCTION

\begin{tabular}{|c|c|c|c|c|c|c|}
\hline $\begin{array}{c}\text { NUMBER OF } \\
\text { HIDDEN } \\
\text { LAYERS }\end{array}$ & $\begin{array}{c}\text { NUMBER OF } \\
\text { NEURONS IN } \\
\text { EACH LAYER AND } \\
\text { ITS TRANSFER } \\
\text { FUNCTION }\end{array}$ & $\begin{array}{l}\text { NUMBER OF } \\
\text { ITERATIONS }\end{array}$ & $\begin{array}{c}\text { EXECUTION } \\
\text { TIME } \\
\text { (IN MIN) }\end{array}$ & GRADIENT & Performance & $\begin{array}{l}\text { ClassifiCation } \\
\text { ACCURACY }\end{array}$ \\
\hline \multirow{5}{*}{2} & $\begin{array}{l}600500 \\
\text { TAN TAN }\end{array}$ & 293 & $0: 40$ & 5.60 & 0.005 & $80 \%$ \\
\hline & $\begin{array}{l}600500 \\
\text { TAN LOG }\end{array}$ & 184 & $0: 24$ & 0.48 & 0.000417 & $50 \%$ \\
\hline & $\begin{array}{l}750600 \\
\text { TAN TAN }\end{array}$ & 277 & 0:54 & 6.87 & 0.00836 & $98.5 \%$ \\
\hline & $\begin{array}{l}700600 \\
\text { TAN TAN }\end{array}$ & 247 & $0: 43$ & 10.4 & 0.024 & $88 \%$ \\
\hline & $\begin{array}{l}700600 \\
\text { TAN LOG }\end{array}$ & 289 & $0: 48$ & 0.311 & $5.2 \mathrm{E}^{-5}$ & $60 \%$ \\
\hline
\end{tabular}




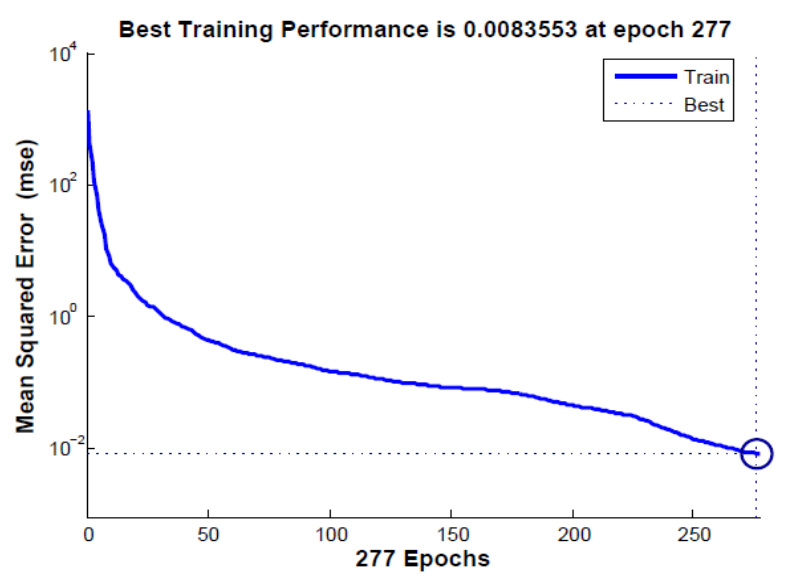

Fig. 14: performance plot of FFNN

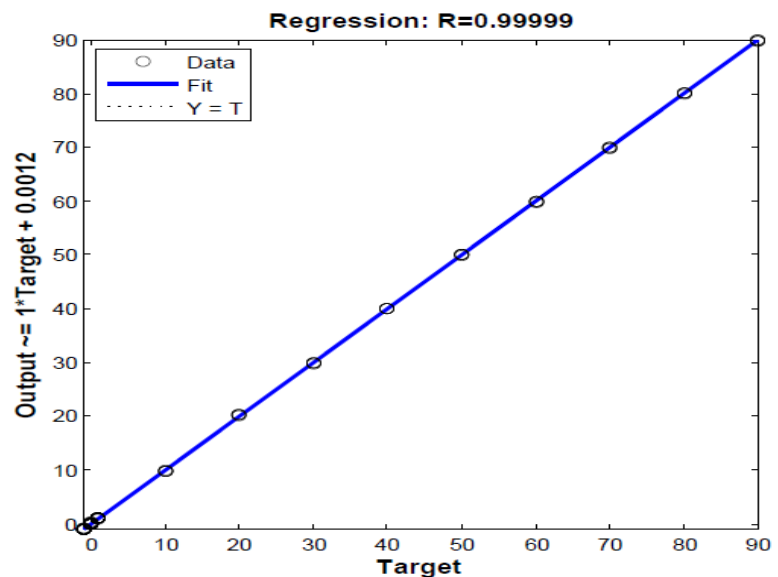

Fig. 15: Regression plot of FFNN

25 additional test data corresponding to each case of the disturbance were generated For the purpose of evaluating the proposed FFNN. Table II gives the classification results for different types of disturbance for FFNN. The accuracy of the classification is $94.1 \%$ for balanced sag, $100 \%$ for balanced swell, unbalanced sag and unbalanced swell as seen in Fig 16. Further prediction accuracy was $100 \%$ for trained data, $98 \%$ of test data and overall accuracy being $98.53 \%$ as seen in Fig 17.

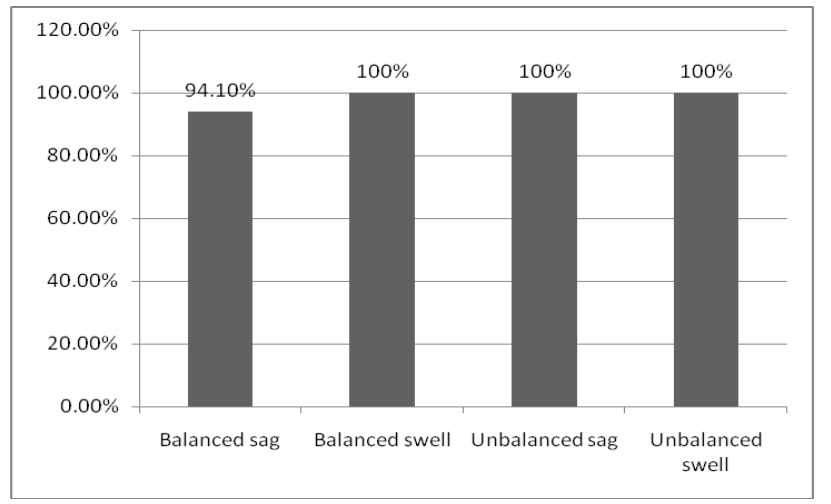

Fig. 16: The accuracy of classification for different types of disturbance

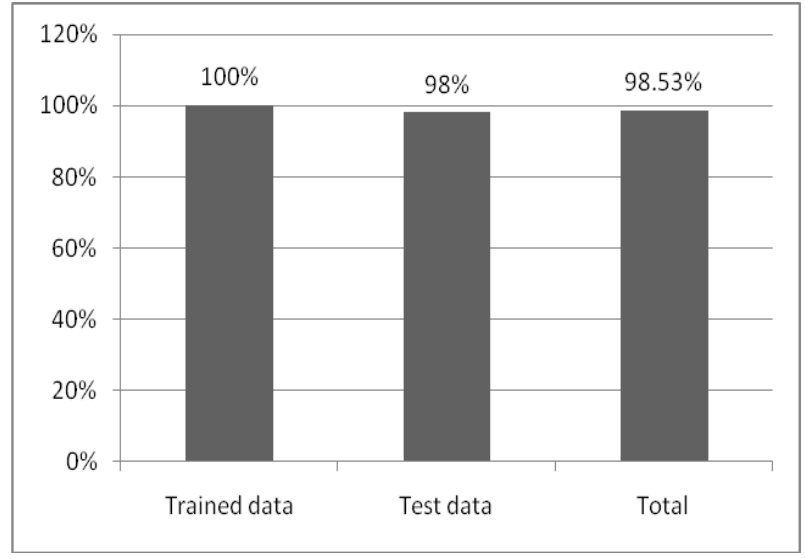

Fig. 17: The accuracy of classification for trained data, testing data, and total data.

TABLE II

THE RESULT OF CLASSIFICATION FOR DIFFERENT TYPES OF DISTURBANCE USING FFNN

\begin{tabular}{|c|c|c|c|c|c|}
\hline Sl. No. & $\begin{array}{c}\text { Type of } \\
\text { disturbance }\end{array}$ & $\begin{array}{c}\text { Trained } \\
\text { data }\end{array}$ & Testing data & Total & Accuracy \\
\hline 1 & Balanced sag & $9 / 9$ & $23 / 25$ & $32 / 34$ & $94.1 \%$ \\
\hline 2 & Balanced swell & $9 / 9$ & $25 / 25$ & $34 / 34$ & $100 \%$ \\
\hline 3 & Unbalanced sag & $9 / 9$ & $25 / 25$ & $34 / 34$ & $100 \%$ \\
\hline 4 & $\begin{array}{c}\text { Unbalanced } \\
\text { swell }\end{array}$ & $9 / 9$ & $25 / 25$ & $34 / 34$ & $100 \%$ \\
\hline & Grand total & $36 / 36$ & $98 / 100$ & $134 / 136$ & $98.53 \%$ \\
\hline \multicolumn{2}{|c|}{ Percentage column wise } & $100 \%$ & $98 \%$ & $98.53 \%$ & - \\
\hline
\end{tabular}




\section{B. Classification using radial basis neural network}

Table III shows the goal, spread, epoch, performance, gradient, validation check, step size and classification accuracy for RBNN. The training function for training the RBNN employs the use of Conjugate gradient backpropagation with Powell-Beale restarts. It is observed that the radial basis network is sensitive to spread but highly sensitive to variation in goal. Hence to obtain an optimal network for good classification, both goal and spread are varied, and the results are tabulated in Table 3 . The network with highest classification accuracy is highlighted in Table 3 and is used for the classification purpose. Fig. 18 shows regression plot for the chosen network. From Fig. 18 it is seen that the target and ANN output values match closely to each other.

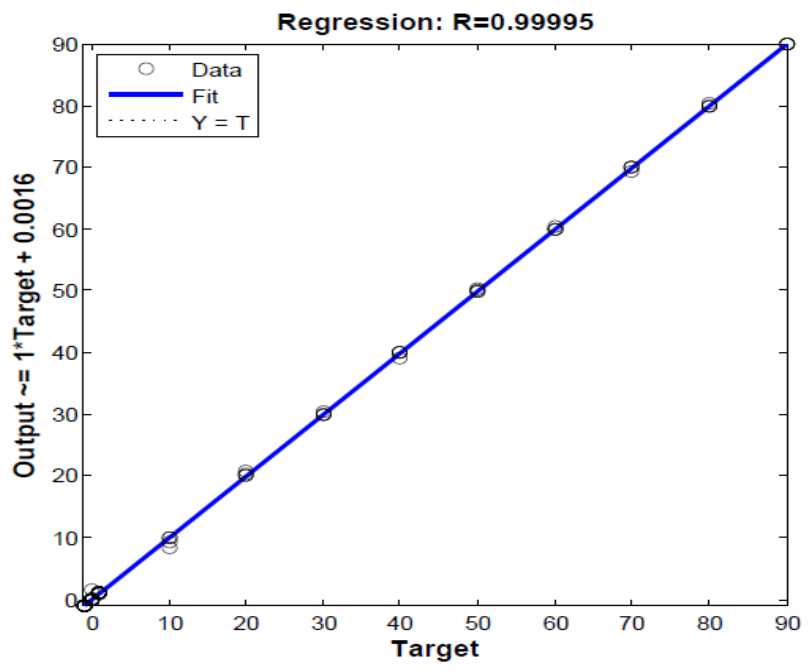

Fig. 18. Regression plot for RBNN

TABLE III

RADIAL BASIS NEURAL NETWORK (RBNN) WITH CONJUGATE GRADIENT BACKPROPAGATION WITH POWELL-BEALE RESTARTS AS TRAINING FUNCTION

\begin{tabular}{|c|c|c|c|c|c|c|c|}
\hline GOAL & SPREAD & EPOCH & PERFORMANCE & GRADIENT & $\begin{array}{c}\text { VALIDATION } \\
\text { CHECK }\end{array}$ & $\begin{array}{c}\text { STEP } \\
\text { SIZE }\end{array}$ & $\begin{array}{c}\text { CLASSIFICATION } \\
\text { ACCURACY }\end{array}$ \\
\hline 0 & 30 & 0 & $8.22 \mathrm{E}^{-28}$ & $1.19 \mathrm{E}^{-11}$ & 0 & 1 & $55 \%$ \\
\hline 0 & 35 & 0 & $2.2 \mathrm{E}^{-27}$ & $2.52 \mathrm{E}^{-11}$ & 0 & 1 & $64 \%$ \\
\hline 0 & 40 & 0 & $1.6 \mathrm{E}^{-27}$ & $2.91 \mathrm{E}^{-11}$ & 0 & 1 & $78 \%$ \\
\hline 0 & 45 & 1 & $4.98 \mathrm{E}^{-27}$ & $1.68 \mathrm{E}^{-10}$ & 0 & 0 & $48 \%$ \\
\hline 0 & 50 & 1 & $1.25 \mathrm{E}^{-27}$ & $1.02 \mathrm{E}^{-10}$ & 0 & 0 & $40 \%$ \\
\hline 0.2 & 65 & 1 & 0.169 & 108 & 0 & 0 & $55 \%$ \\
\hline 0.1 & $\mathbf{6 8}$ & $\mathbf{1}$ & $\mathbf{0 . 0 7 4 6}$ & $\mathbf{1 7 8}$ & $\mathbf{0}$ & $\mathbf{0}$ & $\mathbf{8 9 . 7 \%}$ \\
\hline 0.01 & 68 & 1 & 0.0035 & 6.24 & 0 & 0 & $35 \%$ \\
\hline 0.1 & 68 & 1 & 0.0746 & 178 & 0 & 0 & $67 \%$ \\
\hline
\end{tabular}

Table IV gives the classification results for different types of disturbance for RBNN. The accuracy of classification is $79.41 \%$ for balanced sag and swell, $100 \%$ for unbalanced sag and swell as seen in Fig 19. Further prediction accuracy was
$94.4 \%$ for trained data, $88 \%$ of test data and overall accuracy being $89.7 \%$ as seen in Fig 20. From Fig 21, it is found that the overall performance of RBNN is $89.7 \%$, and FFNN is $98.53 \%$. 
TABLE IV

CLASSIFICATION RESULT FOR DIFFERENT TYPES OF DISTURBANCE USING RBNN

\begin{tabular}{|c|c|c|c|c|c|}
\hline Sl. No. & $\begin{array}{c}\text { TYPE OF } \\
\text { DISTURBANCE }\end{array}$ & $\begin{array}{c}\text { TRAINED } \\
\text { DATA }\end{array}$ & TEST DATA & TOTAL & ACCURACY \\
\hline 1 & Balanced sag & $8 / 9$ & $19 / 25$ & $27 / 34$ & $79.41 \%$ \\
\hline 2 & Balanced swell & $8 / 9$ & $19 / 25$ & $27 / 34$ & $79.41 \%$ \\
\hline 3 & Unbalanced sag & $9 / 9$ & $25 / 25$ & $34 / 34$ & $100 \%$ \\
\hline 4 & Unbalanced swell & $9 / 9$ & $25 / 25$ & $34 / 34$ & $100 \%$ \\
\hline \multicolumn{2}{|c|}{ Grand total } & $34 / 36$ & $88 / 100$ & $122 / 136$ & $89.7 \%$ \\
\hline \multicolumn{2}{|r|}{ Percentage column wise } & $94.4 \%$ & $88 \%$ & $89.7 \%$ & - \\
\hline
\end{tabular}

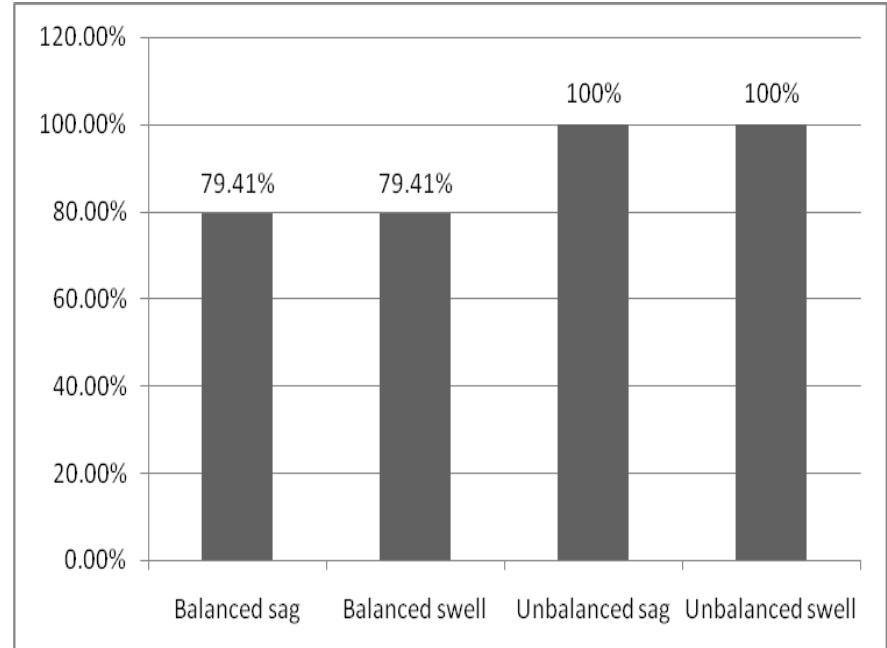

Fig. 19. Classification accuracy for different type of disturbance

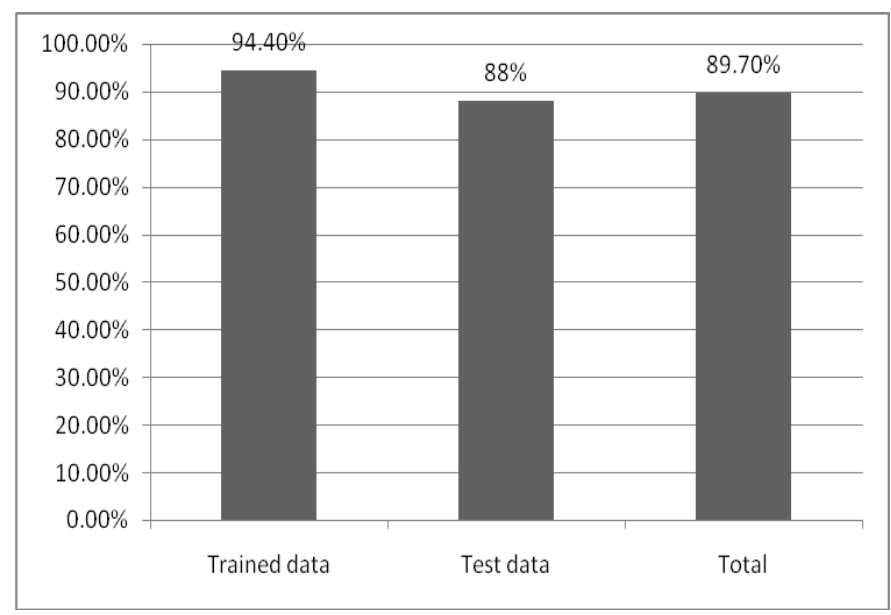

Fig. 20. Classification accuracy for trained data, testing data, and total data for RBNN.

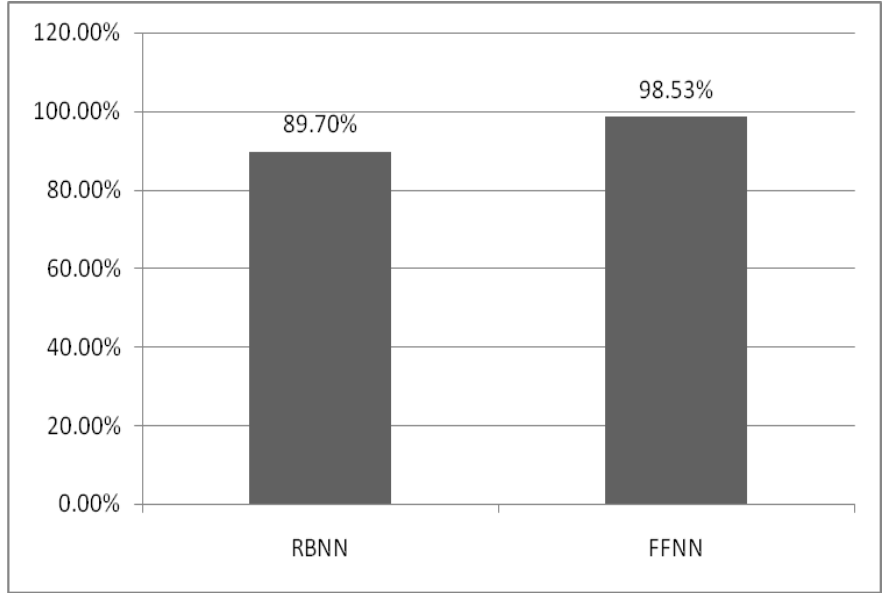

Fig. 21. Classification accuracy of RBNN and FFNN

\section{CONCLUSION}

This paper presents a resourceful new technique for the automatic classification of PQ disturbance in the supply to the induction motor. Supply voltage was varied from $10 \%$ to $90 \%$ for sag, swell, unbalanced sag and unbalanced swell. The wavelet coefficients bear sufficient information regarding the type and percentage of variation in the supply voltage compared to the balanced supply. These wavelet coefficients are fed as input to both RBNN and FFNN and the results are presented in this paper. The FFNN is not only able to detect the PQ disturbances but is also able to determine the percentage of the disturbance more accurately than RBNN. The overall performance evaluation of FFNN is found to be good compared to RBNN. 


\section{REFERENCES}

[1] A. Domijan, G. T. Heydt, A. P. S Meliopoulos, S. S. Venakata and S. west, "Directions of research on power quality", IEEE Transaction on power delivery, 8(1) (1993), pp. 429- 436.

[2] J. Douglas, "Solving power quality problems", EPRI Journal, 18(8) (1993), pp. 6-15.

[3] W. R. A. Ibrahim and M. M. Morcos, "Aritificial intelligence and advanced mathematical tools for power quality applications: A survey", IEEE Trans. power delivery, 17( 2) (2002), pp. 668- 673.

[4] J. Huang, M. Negnevitsky and D.T. Nguyen, "A neural- fuzzy classifier for recognition of power quality disturbances", IEEE Trans. power delivery, 17(4) (2002), pp. 609- 616.

[5] Mamun Bin Ibne Reaz, Florence Choong, Mohd Shahiman Sulaiman, Faisal Mohd. Yasin and Masaru Kamada, "Expert system for power quality disturbance classifier", IEEE Trans. on power delivery, 22(3)(2007), pp. 1979- 1988.

[6] Rajiv Kapoor \& Rashmi Gupta, "Statistically matched wavelet-based method for detection of power quality events," International Journal of Electronics, 98(1) (2011), pp. 109-127.

[7] Valdomiro VEGA, cesar DUARTE and Gabriel ORDONEZ, "Automatic power quality disturbances detection and classification based on discrete wavelet transform and support vector machine", $19^{\text {th }}$ international conference on electricity distribution (CIRED), Vienna, 21-24 May 2007, paper ID 0827.

[8] Ali Asheibi, David Stirling, Sarath Perera and Duane Robinson, "Power quality data analysis using unsupervised data mining", Australasian universities power engineering conference (AUPEC 2004), 26-29 September 2004, Brisbane, Australia.

[9] Whei-Min Lin, Chien-Hsien Wu, Chia-Hung Lin, and Fu-Sheng Cheng," Detection and Classification of Multiple Power-Quality Disturbances with Wavelet Multiclass SVM", IEEE Transactions on power delivery, 23(4)(2008), pp. 2575- 2582.

[10] Murat Uyar, Selcuk Yildiri, Muhsin Tunay Gencoglu, "An expert system based on S-transform and neural network for automatic classification of power quality disturbances", Expert Systems with Applications, 36 (2009), pp. 5962-5975.

[11] Abdel-Galil T.K., Kamel M., Youssef A.M., El-Saadany E.F., and Salama M.M.A.,"Power quality disturbance classification using the inductive inference approach", IEEE Trans. on Power Delivery, 19 (2004), pp. 1812 - 1818.

[12] Harapajan Singh, Manjeevan Seera, and Ahmad Puad Ismail, "Condition monitoring of electrical supply voltage quality to electrical machines using RBF neural network," 2010 IEEE International conference on power and energy (PECon 2010), Nov 29 $9^{\text {th }}-$ Dec $1^{\text {st }}$, Kuala Lumpur, Malaysia, pp. 312- 317.

[13] Bizjak Boris. and Planinsic Peter., "Classification of power disturbances using fuzzy logic", Proc. of IEEE Power Electronics and Motion Control Conference, EPE-PEMC 2006, Portoroz, Slovenia.

[14] B. Biswal, M. Biswal, S. Mishra and R. Jalaja, "Automatic classification of power quality events using balanced neural tree," IEEE Trans. on industrial electronics, 61(1) (2014), pp. 521- 530.

[15] Bollen M.H.J., Gu I.Y.H., Axelberg P.G.V. and Styvaktakis E., "Classification of underlying causes of power quality disturbances: deterministic versus statistical methods", EURASIP Journal on Advances in Signal Processing, 2007, pp.1-17.

[16] Chah keow, P. Nallagownden, K.S. Rama Rao, "Denoising scheme for enhancing power quality problem classification based on wavelet transform and a rule based method", International conference on electrical, control and computer engineering, Malaysia, June $21^{\text {st }}-22^{\text {nd }}$ 2011.

[17] M. Riera-Guasp, Jose A. Antonino-Daviu, M. Pineda- Sanchez, R. Puche- Panadero and J. Perez- Cruz, "A general approach for the transient detection of slip-dependent fault componenets based on the discrete wavelet transform," IEEE transactions on Industrial electronics, 55(12) (2008), pp. 4167-4180.

\section{BIOGRAPHIES}

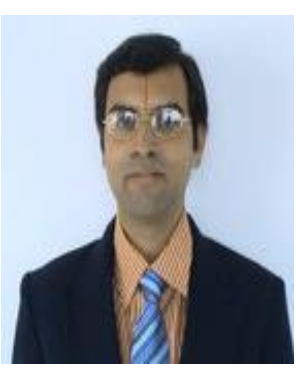

Sridhar. $\mathbf{S}$ received his B.E. degree in Electrical and Electronics Engineering from Bangalore University in 2003 and M.Tech from Visvesvaraya Technological University in 2006. Currently, he is working as assistant professor in the Department of Electrical and Electronics Engineering at RNS Institute of Technology, Bengaluru, India. His research area includes power quality, digital signal processing and intelligent monitoring of electrical machines.

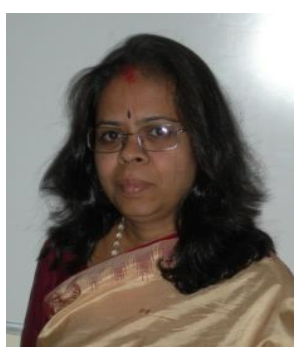

Dr. K. Uma Rao is a professor in the Department of Electrical Engineering, at RV College of Engineering, Bengaluru, India. She completed her Ph.D. from Indian Institute of Science (IISc), Bengaluru. She has over 28 years of teaching and research experience. She has authored 11 technical books in different areas of electrical engineering. She has over 150 technical publications. Her research areas include Power system dynamics, Power Quality, FACTS and Custom power devices.

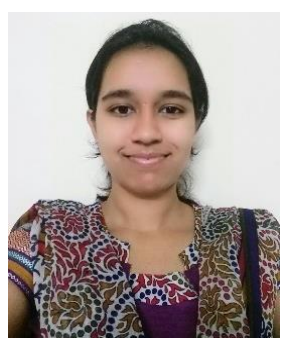

Sukrutha Jade, completed B.E in Electrical and Electronics Engineering from RNS Institute of Technology, Visvesvaraya Technological University. Currently, she is working as an Associate Software Engineer in Robert Bosch Engineering and Business Solutions (RBEI). Her research areas include Automation, Machine learning, and embedded systems. 